\title{
Career choices among medical students in Bangladesh
}

This article was published in the following Dove Press journal:

Advances in Medical Education and Practice

II February 20I I

Number of times this article has been viewed

\author{
SM Moslehuddin Ahmed' \\ Md Anwarul Azim \\ Majumdar ${ }^{2}$ \\ Rezina Karim ${ }^{3}$ \\ Sayeeda Rahman ${ }^{2}$ \\ Nuzhat Rahman ${ }^{4}$ \\ 'Department of Community Medicine. \\ Uttara Adhunik Medical College, \\ Dhaka, Bangladesh; ${ }^{2}$ Department \\ of Clinical Sciences, School of Life \\ Sciences, University of Bradford, \\ West Yorkshire, Bradford, UK; \\ ${ }^{3}$ Department of Microbiology, Uttara \\ Adhunik Medical College, Dhaka, \\ Bangladesh; ${ }^{4}$ Department of Nutrition \\ Sciences, University of Alabama at \\ Birmingham, Birmingham, AL, USA
}

Correspondence: SM Moslehuddin Ahmed Department of Community Medicine, Uttara Adhunik Medical College,

Dhaka 1230, Bangladesh

Tel +880201710972596

Email ofnmosleh@yahoo.com
Introduction: Information regarding career choices of medical students is important to plan human resources for health, design need-based educational programs, and ensure equitable and quality health care services in a country.

Aim: The aim of the study is to identify career choices, nature of career, intended practice locations, and reasons for career choices of Bangladesh medical students.

Method: First-, third-, and fifth-year students of Bangladesh Medical College and Uttara Adhunik Medical College completed a self-report questionnaire on career choices, nature of career, intended practice locations, and reasons for career choices. The students were requested to choose three long-term choices from the given specialties.

Results: A total of 132 students responded (46 males and 86 females) and response rate was $75 \%$. The popular choices (first choice) among males and females were medical specialty, surgical specialty, obstetrics and gynecology, and general practice. For first, second, and third choices altogether, male students chose surgical specialties and female students preferred medical specialties. The leading reasons for selecting a specialty were personal interest and wide job opportunity. More than $67 \%$ of respondents wanted to join private services and about $90 \%$ chose major cities as practice locations. About $43 \%$ of respondents expressed willingness to practice medicine in Bangladesh, whereas $51 \%$ of total respondents wanted to practice abroad.

Discussion: Majority of students intended to specialize in established clinical specialties and subsequently practice in major cities, and more than half wanted to immigrate to other countries. Basic medical subjects and service-oriented (lifestyle-related) and preventive/social medical specialties were found to be less attractive. If this pattern continues, Bangladesh will suffer a chronic shortage of health personnel in certain specialties and in rural areas.

Conclusions: Reorientation of health care and medical education is needed along with policy settings to attract doctors to the scarcity and high-priority disciplines so that imbalances encountered would be minimal in future.

Keywords: career choices, medical students, Bangladesh

\section{Introduction}

In recent years, educational institutions around the world have been increasingly confronted with the challenge of making their curricula relevant to the needs of the time. Medical education in Bangladesh has also experienced many changes and challenges. ${ }^{1-3}$ Medical education system in Bangladesh inherited the typical features of colonial education, which is very much on the traditional pattern: lecture-based, teacher-centered, discipline-based, examination-driven, and hospital-oriented. ${ }^{2}$ The curriculum structure is generally divided into basic sciences and clinical sciences. 
The bachelor of medicine and bachelor of surgery degree is a 5-year program followed by 1-year compulsory logbookbased internship. ${ }^{3}$ The medium of instruction in medical colleges is English.

One of the important developments in recent years in medical education in Bangladesh is the emergence of private medical colleges with the establishment of Bangladesh Medical College (BMC) in the center of Dhaka city (capital) in 1986 by Bangladesh Medical Studies and Research Institute (BMSRI). ${ }^{4}$ Currently, there are 61 medical colleges in Bangladesh, of which 43 are privately funded. ${ }^{5} \mathrm{BMC}$ is now a well-established, leading medical institute in the country, and until now $\sim 2500$ students graduated from BMC. In 2007, BMSRI added a new medical college 'Uttara Adhunik Medical College (UAMC)' at the outskirts of Dhaka city, and it has now two batches of students on year one and three.

Information concerning the career choices of medical students is important in planning the health care workforce and medical education programs and providing equitable and quality health care services to the community. The identification of career preference and intended practice locations of the medical students also provide a useful contribution to the projections, need, and distribution of doctors across different specialties and regions in the country. Choice of a career is a complex personal decision influenced by a multitude of extrinsic and intrinsic factors. Studies conducted in Asian countries demonstrated that medical students usually choose established hospital-based clinical specialties and want to practice in major cities. ${ }^{6-14}$ These create acute shortage of medical teachers in medical colleges ${ }^{15}$ and doctors in rural areas. ${ }^{12,16}$ Moreover, substantial number of medical students wants to join in private medical services. ${ }^{17}$ The new trend of choosing surgical specialties by more female students ${ }^{18}$ and graduates ${ }^{13,14}$ also require special attention by policymakers. Study conducted in Malaysia on three batches of final-year students from 1992 to 1994 identified that $17 \%$ of the female students mentioned surgical specialties as their first, second, or third choice, ${ }^{6}$ and it was increased to $67 \%$ in 2003 cohort of medical graduates. ${ }^{13,14}$ Migration of doctors from Asian countries to the developed world has also posed another concern. ${ }^{19-22}$ It was estimated in 2006 that about $1 \%$ of the total number of practicing physicians of Bangladesh migrated to other countries (eg, Middle East, USA, UK) which was almost $20 \%$ of the average annual graduates from medical colleges. ${ }^{19}$ A recent study conducted among students, interns, and house officers in Nepal found that almost half of them planned to migrate to a developed country. ${ }^{20}$ The important reasons for migration among medical final-year students are poor salary structure, poor quality of training, and poor work environment in their home country. ${ }^{21}$ To the best of our knowledge, until now, no study examined the career choice among medical students in Bangladesh. The main aims of the study were to investigate the first, second, and third career choices of medical students in Bangladesh; their preferred permanent location for practicing medicine; nature of jobs; factors affecting choice of the specialty; and students' willingness to practice medicine in Bangladesh and other countries.

\section{Methods}

A cross-sectional, questionnaire-based study involving medical students of two private medical colleges in Bangladesh was conducted during the period of NovemberDecember 2009. Respondents anonymously completed a self-reported questionnaire which was developed by Majumder et al. ${ }^{13,14,18}$ The questionnaire was modified based on the local context and circumstances and included following sections: demographics, career choices, nature of career, intended practice locations, and reasons for career choices. The specialists and subspecialists taught and/or examined in Bangabandhu Sheikh Mujib Medical University, ${ }^{23}$ National Institute of Preventive and Social Medicine, ${ }^{24}$ and Bangladesh College of Physicians and Surgeons ${ }^{25}$ were incorporated in the questionnaire to be chosen by the students as their career choices. The questionnaire was pretested with a group of students and improved and was then distributed to all the first- and thirdyear students of UAMC, and first-, third-, and fifth-year students of BMC after their lectures. At the time of study, UAMC had only two cohorts of medical students, that is, first year and third year. First-, third-, and fifth-year students of BMC were chosen to examine career choices in important stages of the medical education process. The students were requested to choose three long-term choices from the given specialties and rank them as first, second, and third, that is, one in each preference; one response from nature of career; one response from intended practice location; and one or more response from reasons for choosing a career. Research approval was obtained from college authorities.

\section{Statistical analysis}

All statistical analyses were performed using the Statistical Package for the Social Sciences, version 16.0 (SPSS, Inc, Chicago, IL). Descriptive data are given as frequencies and percentages. Differences in distributions were analyzed by $\chi^{2}$ test. The level of significance was set at $P<0.05$. 


\section{Results}

\section{Response to questionnaire}

Of 176 questionnaires, 132 were completed, producing a response rate of 75\%; 62 from UAMC and 70 from BMC. About $65 \%(n=86)$ of the respondents were female, and number of students from first, third, and fifth year was 32 , 56 , and 44 , respectively.

\section{Career choices: first, second, and third preferences}

The overall findings of the study showed that students chose different specialties of two established disciplines, that is, medicine (40\%) and surgery (35\%), as their first, second, and third choices altogether (Figure 1). The popular subspecialty choices were cardiology, obstetrics and gynecology, internal medicine, pediatrics, cardiac surgery, general surgery, and neurosurgery. There was a significant difference in choosing internal medicine $(P=0.001)$ and obstetrics and gynecology $(P<0.001)$ as first, second, and third choices. Service-related ${ }^{12}$ or lifestyle-related ${ }^{26,27}$ specialties, for example, radiotherapy, oncology, physical medicine, anesthesia, radiology, pathology, microbiology, biochemistry, etc, were found to be less attractive than clinical specialties. Basic medical subjects, general practice, preventive/social medicine, and medical administration/management were also found to be less popular. No students opted for the following specialties/subspecialties as their first, second, and third choices: hematology, physical medicine and rehabilitation, transfusion medicine, infectious diseases and tropical medicine, otolaryngology, community ophthalmology, general pathology, virology, health education, maternal and child health, medical entomology, nutrition and biochemistry, microbiology and mycology, parasitology, and population dynamics.

For first, second, and third choices altogether, first-year students chose surgery (48\%) than medicine (30\%) specialty (Figure 2). However, medicine became the more preferred specialty than surgery among third (39\% vs $32 \%$ ) and fifthyear $(50 \%$ vs $28 \%)$ students. Less number of fifth-year students selected obstetrics and gynecology and basic medical subjects in comparison to first- and second-year students. However, more fifth-year students chose general practice and medical administration than first- and third-year students.

\section{Career choices: first preferences}

Among the first preferences, a total of 99 (75\%) students were attracted to the two established specialties: medicine (44\%) and surgery (excluding obstetrics and gynecology) (31\%) (Figure 1). The most popular subspecialty choices were internal medicine, cardiology, obstetrics and

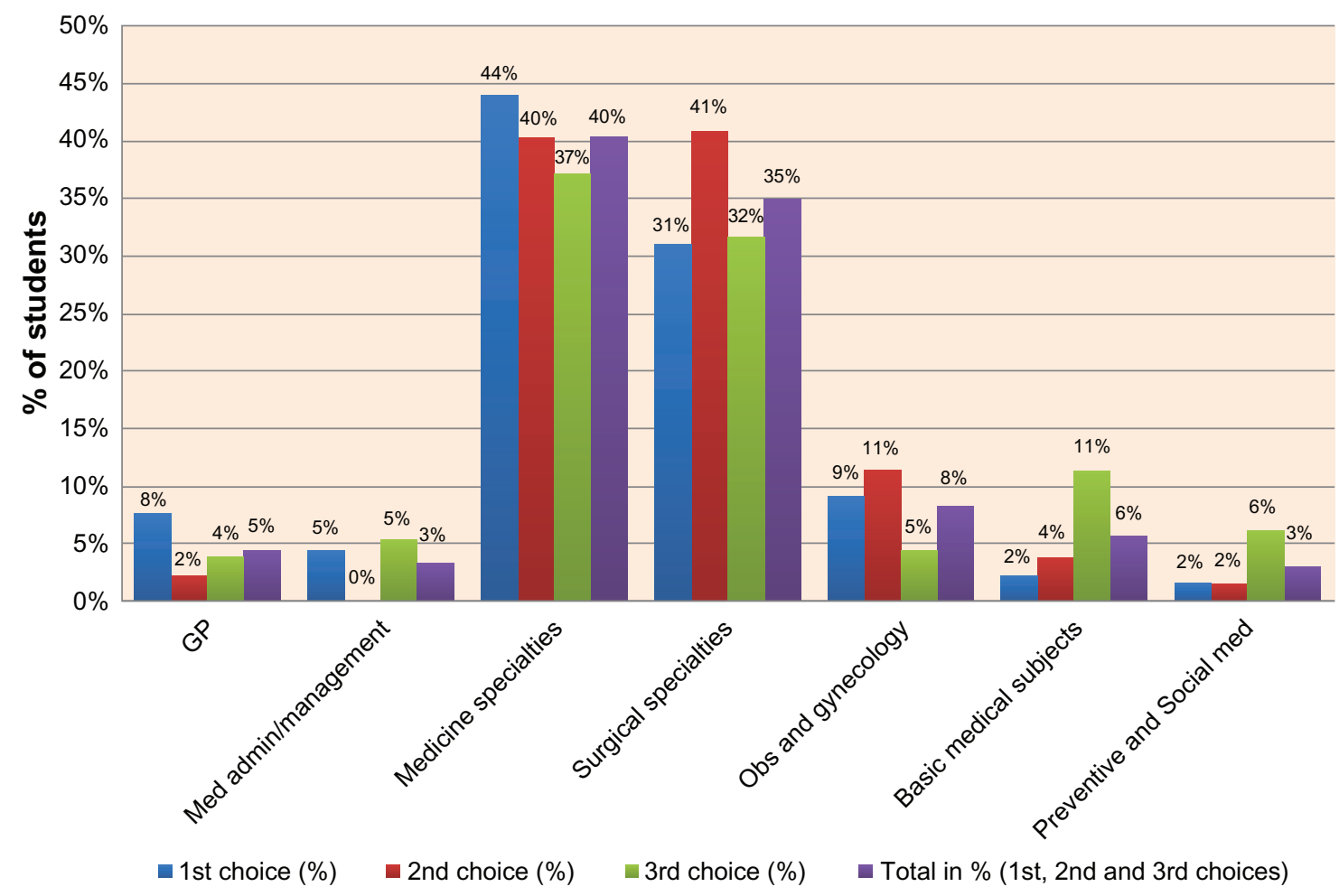

Figure I Comparison of career choices. 


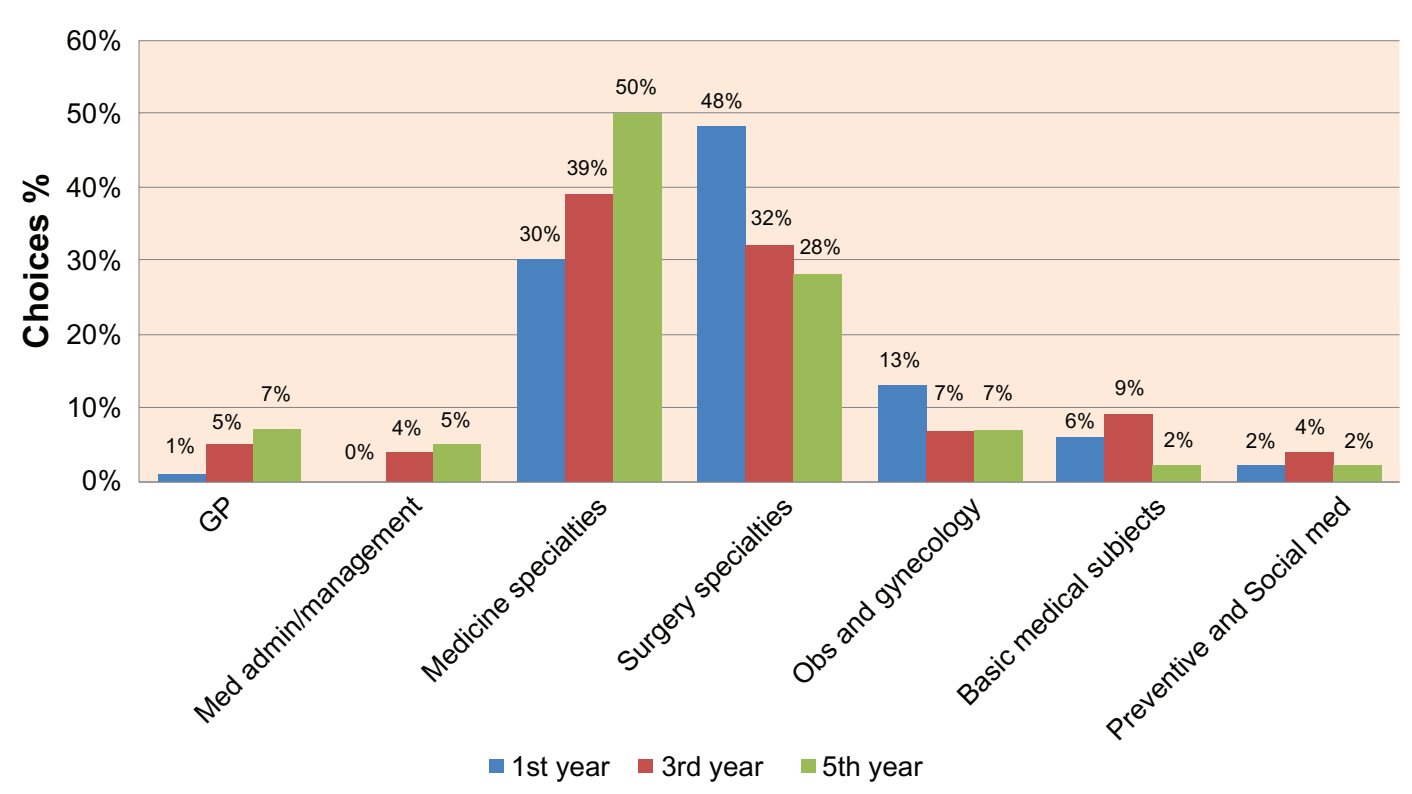

Figure 2 Year wise comparison of career choices (first, second, and third choices).

gynecology, cardiac surgery, pediatrics, general surgery, and neurosurgery. Students paid very low preferences to medical administration/management, basic medical subjects, and preventive and social medicine. There was a significant difference in choosing specialties and subspecialties as first preference among first-, third-, and fifth-year students $(P<0.05)$.

\section{Career choices: second and third preferences}

Among the second and third preferences, a similar pattern emerged like first preference; most of the respondents chose two established specialties: medicine and surgery (Figure 1). Basic medical subjects, preventive and social medicine, and medical administration/management appeared considerably more often as the third preferences than either as the first or second (Figure 1).

Unlike first choice, respondents selected surgical specialties (41\%) than medical specialties $(40 \%)$ as their second choice (Figure 1). The most popular subspecialty choices were obstetrics and gynecology, cardiology, general surgery, cardiac surgery, pediatrics, and neurosurgery.

In third choices, medical specialties (37\%) were found to be more popular than surgical specialties $(32 \%)$. The most popular subspecialty choices were medical administration and management, cardiology, pediatrics, psychiatry, internal medicine, obstetrics and gynecology, and urology. In the third choices, more respondents chose basic medical subjects than first and second preferences (Figure 1).

\section{Career choices: male and female students}

For first, second, and third choices altogether, male students chose surgical specialties ( $45 \%$ vs $37 \%$ ) and female students preferred medicine specialties ( $42 \%$ vs $29 \%$ ) (Figure 3). Male students showed interest in cardiac surgery, internal medicine, cardiology, neurosurgery, and general surgery, whereas female graduates chose obstetrics and gynecology, pediatrics, cardiology, internal medicine, general surgery, cardiac surgery, general practice, and psychiatry. More female students chose basic medical subjects than their male counterparts. Female students were also found to be more inclined to surgical specialties than obstetrics and gynecology.

In first choice, medical specialty was more popular option among male (43.4\%) and female (44.2\%) respondents followed by surgical specialty ( $34.8 \%$ and $29.1 \%$, respectively) (Figure 3). In second and third choices, more male students selected surgical specialty and more female students chose medicine (Figure 3). Female respondents chose surgical specialties than obstetrics and gynecology as first, second, and third choices altogether. A significant difference was observed in selecting specialties and subspecialties as third preference between male and female students $(P<0.05)$.

\section{Career choices: factors responsible}

Both male and female graduates indicated the following as the most important determinants for career choice: personal interest, wide job opportunity, helping people, and income (Figure 4). $\chi^{2}$ analysis revealed significant differences between male and female on the following factors: income, 


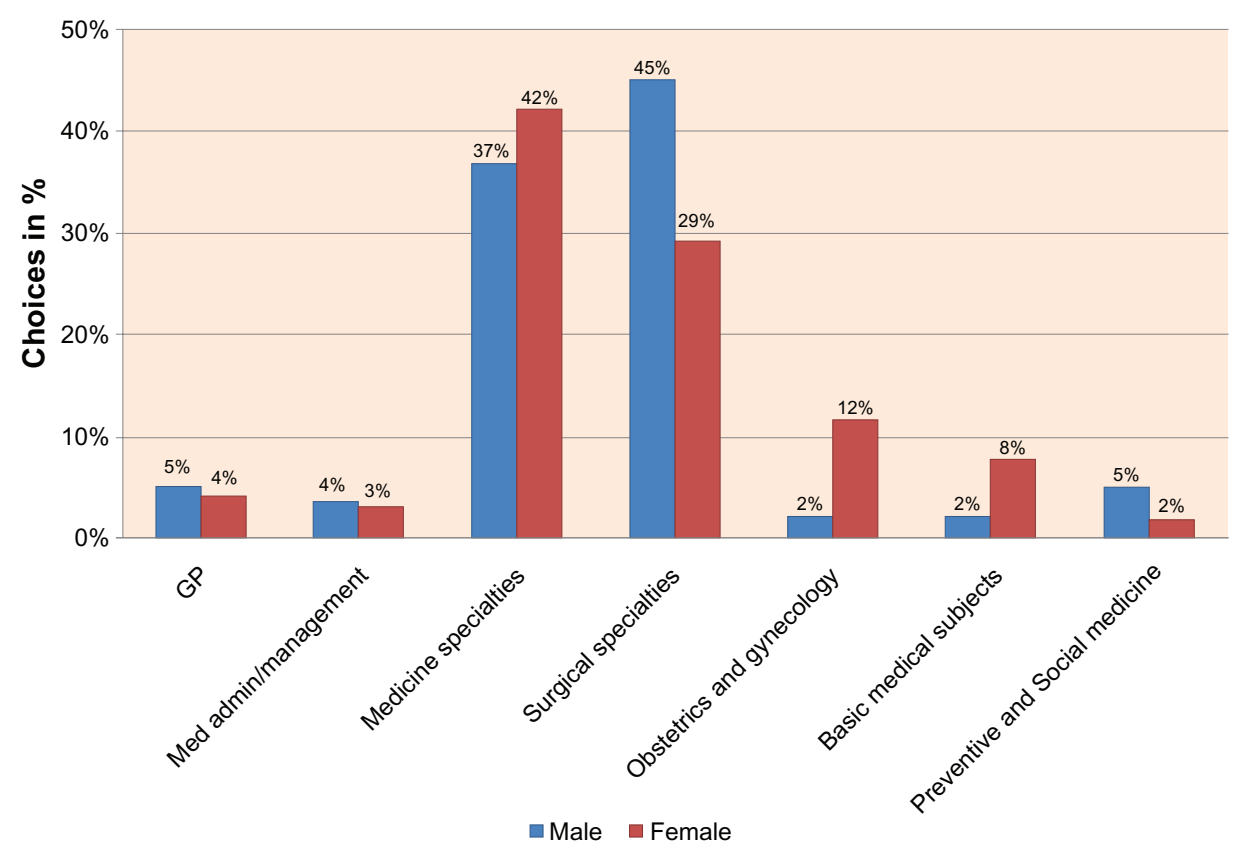

Figure 3 Comparison of career choices between male and female students (first, second, and third choices).

wide job opportunity, academic/teaching prospect, helping people, and fixed hours of work $(P<0.05)$.

\section{Nature and preferred place of employment}

More than $67 \%$ of the respondents wanted to join private medical services followed by government services $(25 \%)$, armed forces (5\%), and nongovernment organization (3\%). When asked to select their preferred place of employment, the most frequently chosen locations were Dhaka city $(64 \%)$ and city with medical colleges (24\%). Other options were subdistrict government health centers (5\%), rural areas (4\%), district hospitals (3\%), and cities without medical college $(<1 \%)$. A statistically significant difference was observed between
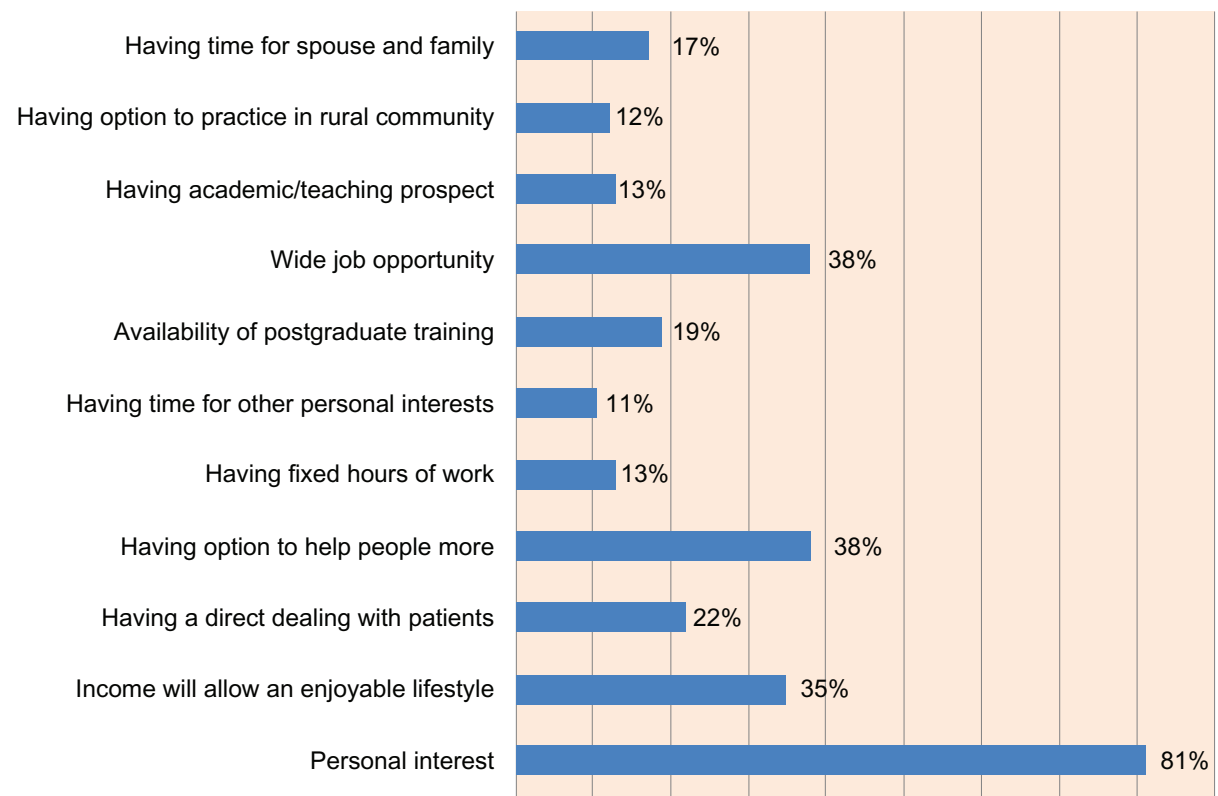

Figure 4 Factors responsible for choosing the specialists. 
preferred place of employment and choosing specialties and subspecialties (as first preference (0.002) and third preferences (0.000)). About $43 \%$ of students expressed their definitive willingness to practice medicine in Bangladesh for the foreseeable future (Table 1), whereas $51 \%$ of the total respondents (who were not certain to practice medicine in Bangladesh) wanted to practice medicine abroad (Table 2).

\section{Discussion}

The present study shows that majority of the students intended to specialize in established hospital-based clinical specialties and subsequently practice in major cities, as shown in the previous studies conducted in other Asian countries. ${ }^{6-14}$ In contrast, only a small proportion of students intended to specialize in the 'service' or 'lifestyle' specialties - studies from Asian ${ }^{6,7,12-14}$ and other countries ${ }^{26,27}$ supported that a controllable lifestyle has become an increasingly important factor in choosing a specialty by medical students. The following are the other notable findings of the present study: i) only a few respondents opted for basic medical subjects, preventive/social medicine, general practice, and medical administration/management; ii) female graduates were more interested in surgery subspecialties than obstetrics and gynecology; iii) less than one-tenth of the respondents were interested to practice in rural areas including subdistrict (upazilla) government health centers; iv) more than two-thirds of the female students wanted to join in private services; v) only one-fourth of the doctors intended to join in government services; vi) about half of the respondents expressed their willingness to practice abroad; and vii) marked differences were observed in selecting major specialties among first-, third-, and fifth-year students.

The study findings hold some important implications, which are not consistent with the health care and medical education mission and vision of Bangladesh. The country needs more academics in basic and service-related (lifestyle-related) subjects in the medical colleges and doctors to practice in rural areas. At present, there are shortages of service specialists in health care services, and most of the positions are

Table I Respondents willingness to practice medicine in Bangladesh

\begin{tabular}{lll}
\hline $\begin{array}{l}\text { Practice medicine } \\
\text { in Bangladesh }\end{array}$ & $\begin{array}{l}\text { Respondents } \\
(\mathbf{n}=\mathbf{~ 1 3 2 )}\end{array}$ & $\%$ \\
\hline Yes, definitely & 57 & 43.2 \\
Yes, probably & 38 & 28.8 \\
Uncertain & 17 & 12.9 \\
No, probably not & 18 & 13.6 \\
No, definitely not & 2 & 1.5 \\
\hline
\end{tabular}

Table 2 Respondents willingness to practice abroad

\begin{tabular}{lll}
\hline Did not answer 'yes, definitely' & $\begin{array}{l}\text { Respondents }^{\mathbf{a}} \\
(\mathbf{n = 7 2 )}\end{array}$ & $\%$ \\
\hline Practice abroad & 67 & 93 \\
Leaving medicine but remaining in Bangladesh & 2 & 2.8 \\
Leaving medicine and leaving Bangladesh & 3 & 4.2 \\
\hline
\end{tabular}

Notes: aRespondents who did not answer 'yes, definitely' in Table I. Totals do not equal to total respondents because of some missing answers.

lying vacant in the district and subdistrict government health centers. The medical colleges are also facing difficulties recruiting and retaining teachers for nonclinical and other basic medical departments in peripheral medical colleges.

As less numbers of 'tomorrow's doctors' are interested in serving the rural people, misdistribution of doctors between urban and rural areas may constitute a major problem in future. Moreover, the loss of interest in government service is an alarming observation, which may obviously be related to the promise of greater money and facilities in private sector compared to government sector. ${ }^{17}$ Appropriate action should be taken to create a conducive working environment to attract doctors for government sector, otherwise provision of providing adequate health care to the community will be difficult in future. Bangladesh implemented a communityoriented and competency-based medical curriculum since 1988 with an aim to produce need-based doctors to provide quality health care to the community. ${ }^{1-3}$ The findings of the present study highlight the need for major review of medical curriculum toward more effective community-orientation and restructuring of community-based teaching to ensure adequate exposure of medical students to health care problems in rural settings. Appropriate career counseling and perhaps some inducement are also necessary to attract graduates to practice in suburban and rural areas.

Another issue is migration of doctors to other countries which needs special attention by the policymakers as half of the study population expressed their willingness to migrate to other countries. Study conducted by Majumder et al ${ }^{13,14}$ in Malaysia demonstrated that $75 \%$ of the medical graduates wanted to build their career after graduation in their own country, which may be related to the better socioeconomic and working condition of the country and motivation received through undergraduate educational process. Medical graduates tend to concentrate themselves in urban cities for a number of reasons, and banning migration would not redress the imbalances of doctors in urban-rural areas. ${ }^{21,22}$ To reduce migration and increase retention of doctors in rural areas, a national policy should be formulated to improve salaries and working conditions; ${ }^{21,22}$ reorient medical education; ${ }^{22}$ and 
train and mobilize more paramedics and community health workers to rural areas, which would be more cost-effective and who are less likely to emigrate. ${ }^{22}$ It is a common assumption that migration of doctors will affect the access to and quality of health care and will ultimately impair the ability of the health care system to achieve health objectives of the country. However, research suggests that permanent migration, if managed properly, could become a successful form of trade (remittances) in services, as evidences shown in Cuba, India, and the Philippines. ${ }^{28,29}$

The increased choice of surgical specialties among female graduates shows a new trend. Previous studies ${ }^{8,9}$ showed that women preferred 'soft specialties' (eg, pediatrics) which do not have negative impacts on their family and social life. ${ }^{30,31}$ The combination of domestic responsibilities and professional career demands is found to be mainly responsible for such choices. Extremely long working hours, gender discrimination, harassment, unequal promotion, and negative perception about surgeons in terms of their family life restrict the women's choices of career in 'traditional male specialties', for example, surgery. ${ }^{31-34}$ Such 'cumulative career disadvantages' and 'microinequalities' lead them to opt for careers that let them have a family and social life. ${ }^{33}$ In view of increasing proportion of enrolment of female students in the medical colleges in Bangladesh (eg, $52 \%$ of the students are female who are finally selected for admission in medical colleges for the 2011-2012 session), it is imperative to know their career aspirations and to create a conducive work environment for the females who want to be surgeons. Provision of flexible working patterns, including shift work, part-time training, liberal maternity leave policies, crèche facilities, as well as change of attitude of women graduates, employers, and peers, can help to improve the position of women in medicine.

It is paramount to note that 'income leads to enjoyable lifestyle' (35\%) had less significant influence on the choice of career than 'personal interest' (81\%) and 'opportunity to help people' $(38 \%)$. However, it is a real concern that only $38 \%$ of the respondents selected 'helping people' as motivator to choose a career. Medical colleges and policymakers should ensure that students inculcate and retain adequate professionalism throughout their career, as most of the respondents preferred to join private services after graduation.

\section{Study limitations}

Our work represents an initial effort to identify the nature and reasons for career choices of medical students.
This cross-sectional study involved only two private medical colleges (out of 61 medical colleges in the country) based in the capital city and had a small sample size; therefore, caution needs to be taken to generalize the data to public and periphery medical colleges.

\section{Conclusion}

Although the sample size of the study is small, the findings are certainly interesting enough to warrant further investigation. The pattern of the career choices of medical students in two medical colleges that were observed in this study is no different from the studies carried out in other countries, where the major clinical specialties are more preferred. If this pattern of career choice continues, over the years, Bangladesh will suffer a chronic shortage of competent human resources in certain specialties and in rural areas. As this study showed marked differences in selecting specialties among first-, third-, and fifth-year students, long-term follow-up studies should be conducted to examine early preferences and eventual choices of students and graduates and the point at which intervention is more beneficial. ${ }^{35-37}$ Reorientation of medical education is needed along with policy settings to attract doctors to the scarcity and high-priority disciplines so that imbalances encountered would be minimal in future. Research on medical education needs to be conducted, findings should guide policy settings, and policies need to be implemented to bring quantitative and qualitative changes in medical education and health care..$^{38,39}$

\section{Acknowledgments}

The authors thank the teachers and students of BMC and UAMC who helped and participated in the study.

\section{Authors' contributions}

MAAM conceived of the study, designed the questionnaire, interpreted the data, drafted the manuscript, and revised it. SMMA conceived of the study with MAAM, acquired the data, conducted the data analysis, interpreted the data, and revised the manuscript. RK acquired the data, interpreted data, and revised the manuscript. SR participated in study design, conducted the data analysis, interpreted the data, and revised the manuscript. NR interpreted the data and critically revised the manuscript. All authors approved the final manuscript.

\section{Disclosure}

The authors report no conflicts of interest in this work. 


\section{References}

1. Majumder MAA. A review of the undergraduate medical curriculum in Bangladesh. Bangladesh Med J. 2002;31:47-49.

2. Majumder MAA. Medical education in Bangladesh: past successes, future challenges. Bangladesh Med J. 2003;32:37-39.

3. Amin Z, Merrylees N, Hanif A, Talukder MH. Medical education in Bangladesh. Med Teach. 2008;30(3):243-247.

4. Bangladesh Medical Studies and Research Institute Prospectus Session 2008-2009. Dhaka: BMSRI, Uttara Adhunik Medical College; 2008.

5. Results of public medical colleges published. The Daily Star. October 26, 2010.

6. Zulkifli A, Rogayah J. Career preferences of male and female medical students in Malaysia. Med J Malaysia. 1997;52(1):76-81.

7. Zulkifli A, Rogayah J. Career preferences of medical students of Universiti Sains Malaysia. Malaysian J Med Sci. 1996;3(1):58-61.

8. Shahabuddin SH. Career choice of final-year female medical students at Universiti Kebangsaan Malaysia (UKM). Med J Malaysia. 1986; 41(4):327-330.

9. Razali SM. Medical school entrance and career plans of Malaysian medical students. Med Educ. 1996;30(6):418-423.

10. Huda N, Yousuf S. Career preference of final year medical students of Ziauddin Medical University. Educ Health (Abingdon). 2006;19(3): 345-353.

11. Al-Faris E, Kalantan K, Al-Rowais N, et al. Career choices among Saudi medical students. Acad Med. 1997;72(1):65-67.

12. Karalliedde LD, Senanayake N, Aluwihare AP. Career preferences of the 1984 medical graduates of Sri Lanka. Med Educ. 1986;20(1):64-68.

13. Majumder MAA, Rahim AFA, Rogayah J, et al. Career choices of the 2003 medical graduates of Universiti Sains Malaysia. Poster presentation in the 8th National Conference on Medical Sciences, Universiti Sains Malaysia, 8-9 May, 2003, Kelantan, Malaysia. Malaysian J Med Sci. 2003;10(2):164.

14. Majumder MAA, Rahim AFA, Rogayah J, et al. Specialty choices, predictive factors and intentions to practice in Malaysia: a survey among the recent medical graduates of Universiti Sains Malaysia (USM). Conference booklet of 4th Asia-Pacific Conference on Science and Technology, 23-25 September, 2003, Kuala Lumpur, Malaysia.

15. Ananthakrishnan N. Acute shortage of teachers in medical colleges: existing problems and possible solutions. Natl Med J India. 2007;20(1): 25-29.

16. Rogayah J, Ahmed Z. Career preferences of medical students in a community-oriented medical school. Ann Network Community Oriented Educ. 1993;6:301-310.

17. Lal P, Malhotra C, Nath A, Malhotra R, Ingle GK. Career aspirations and apprehensions regarding medical education among first year medical students in Delhi. Indian J Community Med. 2007;32(3):217-218.

18. Majumder MAA, Rahim AFA, Rogayah J, et al. Are surgical subspecialities still perceived as a man's profession? Sharing a Malaysian experience. Conference proceedings. Abstract for oral presentation in the 9th National Conference on Medical Sciences, Universiti Sains Malaysia, 22-23 May, 2004, Kelantan, Malaysia.

19. Rahman MO, Khan R. Out-migration of health professionals from Bangladesh: prospects of diaspora formation for homeland development. Asian Population Stud. 2007;3(2):135-151.
20. Lakhey M, Lakhey S, Niraula SR, Jha D, Pant R. Comparative attitude and plans of the medical students and young Nepalese doctors. Kathmandu Univ Med J (KUMJ). 2009;7(26):177-182.

21. Syed NA, Khimani F, Andrades M, Ali SK, Paul R. Reasons for migration among medical students from Karachi. Med Educ. 2008; 42(1):61-68.

22. Aly Z, Taj F. Why Pakistani medical graduates must remain free to emigrate. PLoS Med. 2008;5(1):e2.

23. Bangabandhu Sheikh Mujib Medical University (BSMMU). Available from: http://www.bsmmu.org/. Accessed December 12, 2010.

24. National Institute of Preventive and Social Medicine (NIPSOM). Available from: http://www.nipsom.org/. Accessed December 12, 2010.

25. Bangladesh College of Physicians and Surgeons (BCPS). Available from: http://www.bcpsbd.org/. Accessed December 12, 2010.

26. Wu JJ, Tyring SK. The academic strength of current dermatology residency applicants. Dermatol Online J. 2003;9(3):22.

27. Schwartz RW, Jarecky RK, Strodel WE, Haley JV, Young B, Griffen WO Jr. Controllable lifestyle: a new factor in career choice by medical students. Acad Med. 1989;64(10):606-609.

28. Forcier MB, Simoens S, Giuffrida A. Impact, regulation and health policy implications of physician migration in OECD countries. Hum Resour Health. 2004;2(1):12.

29. Record R, Mohiddin A. An economic perspective on Malawi's medical "brain drain". Global Health. 2006;2:12.

30. Colletti LM, Mulholland MW, Sonnad SS. Perceived obstacles to career success for women in academic surgery. Arch Surg. 2000;135(8): 972-977.

31. Dillner L. Why are there not more women consultants? BMJ. 1993; 307(6910):949-950.

32. Showalter E. Improving the position of women in medicine: will not be achieved by focusing only on the problems of women. BMJ. 1999; 318(7176):71-72.

33. Baxter N, Cohen R, McLeod R. The impact of gender on the choice of surgery as a career. Am J Surg. 1996;172(4):373-376.

34. Majumder MAA. Is surgical specialty still perceived as a man's profession? Rapid responses to "Women in medicine" by Kathy Oxtoby in BMJ Careers. Available from: http://careers.bmj.com/careers/advice/ view-rapid-responses.html?id=20000586. Accessed December 12, 2010 .

35. Manuel RS, Borges NJ, Jones BJ. Person-oriented versus techniqueoriented specialties: early preferences and eventual choice. Med Educ Online. 2009;14:4.

36. Goldacre MJ, Laxton L, Lambert TW. Medical graduates' early career choices of specialty and their eventual specialty destinations: UK prospective cohort studies. BMJ. 2010;341:c3199.

37. Edwards C, Lambert TW, Goldacre MJ, Parkhouse J. Early medical career choices and eventual careers. Med Educ. 1997;31(4): 237-242.

38. Majumder MAA. Issues and priorities of medical education research in Asia. Ann Acad Med Singapore. 2004;33(2):257-263.

39. Majumder MAA, Rahman S, D’Souza UJA, Elbeheri G, Abdulrahman KB, Huq MM. Supporting medical students with learning disabilities in Asian medical schools. Adv Med Educ Pract. 2010; $1: 31-39$.
Advances in Medical Education and Practice

\section{Publish your work in this journal}

Advances in Medical Education and Practice is an international, peerreviewed, open access journal that aims to present and publish research on Medical Education covering medical, dental, nursing and allied healthcare professional education. The journal covers undergraduate education, postgraduate training and continuing medical education

\section{Dovepress}

including emerging trends and innovative models linking education, research, and healthcare services. The manuscript management system is completely online and includes a very quick and fair peer-review system. Visit http://www.dovepress.com/testimonials.php to read real quotes from published authors. 